\title{
Concepções e práticas pedagógicas dos docentes para o cuidado clínico de enfermagem
}

\author{
Jamille Forte Viana* \\ Janieiry Lima de Araujo ** \\ Lucilane Maria Sales da Silva* \\ Maria do Socorro de Araujo Dias *** \\ Raimundo Augusto Martins Torres *
}

\begin{abstract}
RESUMO
Pesquisa exploratória e qualitativa cujo objetivo foi analisar as concepções e práticas pedagógicas na formação de enfermagem para efetivação do cuidado clínico. Participaram da pesquisa 30 docentes-enfermeiros de duas Universidades públicas e uma privada de Fortaleza/CE. A coleta de dados ocorreu mediante entrevista semiestruturada. Após a análise de conteúdo, três categorias emergiram: (A) Formação e Trajetória profissional; expressa as motivações dos enfermeiros para atuarem na docência, para os entrevistados o ato de ensinar surge durante sua trajetória profissional como evento natural e pessoal; (B) Concepções sobre Cuidado, Clínica e Enfermagem, revela como os docentes definem o cuidado clínico de enfermagem, este visto como ato de solidariedade fundamentado em conhecimentos científicos e práticos da enfermagem e de outras ciências. O cuidado deve ser pautado na integralidade com vistas a efetivação da clínica ampliada e (C) Concepções Pedagógicas para o Ensino do Cuidado Clínico em Enfermagem, expõe o pensar e o fazer da enfermagem ao atuar na formação de enfermeiros, nessa categoria os entrevistados colocam que apesar do forte apego ao uso da pedagogia tradicional, no cotidiano da sala de aula é perceptível mudanças metodológicas na prática docente que buscam construir uma enfermagem crítica e reflexiva. Assim, para criar uma enfermagem dinâmica e inovadora é necessário que a prática docente supere desafios inerentes ao ensino do cuidado clínico de enfermagem de modo a ressignificar as concepções e práticas pedagógicas que orientam a formação, a construção da ciência e a qualificação para a docência na área.
\end{abstract}

Palavras-chave: Prática do docente de enfermagem. Ensino. Cuidados de enfermagem.

\section{INTRODUÇÃO}

Mudanças nos modos de vida e organização social advindas do processo de globalização e reestruturação da economia mundial demanda uma nova perspectiva de educação, principalmente, no ensino das profissões de saúde. Avanços nas áreas da informação, da mídia digital e da biotecnologia têm interferido diretamente na prática docente (BELLO; BUENO, 2012).

A ideia do professor como agente principal do processo ensino-aprendizagem fato que coloca o aluno como coadjuvante ainda prevalece. A metodologia tradicional centrada na transmissão de conhecimentos e no alcance de resultados cuja avaliação de desempenho é basicamente quantitativa se mostra hegemônica. Este método orienta as concepções e práticas pedagógicas dos docentes desde a educação fundamental perpassa pelo ensino técnico-profissionalizante e alcança o ensino superior. Portanto, esta realidade se coloca para os pesquisadores como uma problemática a ser investigada (GADOT'TI, 2000; FREITAS et al., 2016).

O problema é epistemológico e organizacional e se encontra na contraposição entre o uso da pedagogia tradicional cuja prática docente ocorre desvinculada da realidade social, com o tempo o aluno perde a capacidade de sujeito ativo do próprio aprendizado, tornando-se alienado à realidade com baixa capacidade para transformá-la; ou o uso da pedagogia crítica e reflexiva, fundamentada na construção do conhecimento a partir da problematização da realidade, na articulação entre teoria e prática e na

* Faculdade de Enfermagem, Universidade Estadual do Ceará, UECE, Fortaleza, CE.

** Faculdade de Enfermagem, Universidade do Estado do Rio Grande do Norte, UERN, Pau dos Ferros, RN. E-mail: janieiry@hotmail.com

*** Faculdade de Enfermagem, Universidade Estadual do Vale do Acaraú, Sobral, CE. 
participação ativa e autônoma do aluno no processo ensino-aprendizagem (GADOTTI, 2000; FREIRE, 2011a; FREIRE, 2011b; FREITAS et al., 2016).

No contexto da formação de profissionais para o trabalho em saúde observa-se práticas docentes cuja pedagogia tradicional tem produzido seguidores de normas e condutas ao invés de formar sujeitos críticos-reflexivos. É necessário formar profissionais de saúde alinhados aos princípios científicos, as políticas de saúde vigentes e as necessidades de saúde e perfis de adoecimento da população (CECCIM; MERHY, 2009; CHAVES; CECCIM, 2015).

$\mathrm{Na}$ formação em enfermagem o cuidado deve ocupar posição central no ensino-aprendizagem. Nesse sentido, deslocar o foco do ensino do treinamento para a educação, da técnica para a compreensão, do conteúdo estrito para a tomada de consciência crítica é o caminho para a transformação. Pois, a qualidade da educação reflete significativamente na qualidade do cuidado de enfermagem (RODRIGUES; MENDES SOBRINHO, 2007; SOUZA; VALENTE, 2017; CRUZ et al., 2017).

$\mathrm{Na}$ atualidade, a enfermagem brasileira vem conduzindo sua prática pedagógica para o trabalho em saúde seguindo as Diretrizes Curriculares Nacionais (DCN), parâmetros de reorientação curricular para formar profissionais capazes de oferecer cuidado integral, com vistas a promover a saúde, prevenir agravos e doenças, recuperar e reabilitar (SILVA; SOUZA; FREITAS, 2011).

As DCN-Enfermagem vigentes orientam a prática docente de modo a considerar os saberes prévios do aluno, a troca de experiências, a responsabilidade sanitária e social, o respeito a cidadania e direitos humanos no transcurso do processo ensinoaprendizagem. Enfatiza formar enfermeiro generalista cuja concepção de cuidado de enfermagem seja referencial teórico basilar no transcurso da formação (SILVA; SOUZA; FREITAS, 2011).

Em 2012, a Associação Brasileira de Enfermagem (ABEN) iniciou o debate para a construção coletiva das novas DCNs para a área. Como resultado, uma minuta foi elaborada em Fóruns de discussão com a participação de representantes das sessões estaduais, associados, escolas vinculadas e especialistas em educação em enfermagem. As mudanças apontadas reforçam a integração teoria e prática, a formação interdisciplinar, a garantia de participação dos enfermeiros dos serviços nas atividades práticas e estágio curricular supervisionado (TEXEIRA, 2017).

Além dessas mudanças, a formação deverá atuar na defesa da vida e do Sistema Único de Saúde (SUS); atendimento às necessidades sociais de saúde; integralidade e redes de atenção à saúde; integração ensino-serviço-gestão-comunidade; formação para o trabalho Interprofissional; projetos pedagógicos e componentes curriculares coerentes com as necessidades sociais de saúde; metodologias que privilegiem a participação dos estudantes no processo ensino-aprendizagem; protagonismo estudantil; comunicação em saúde e tecnologias da informação e comunicação; avaliação não somente de conteúdo, mas com caráter formativo emancipatório; pesquisas e tecnologias de interesse dos serviços e comunidades; e formação presencial (TEIXEIRA, 2017).

Face ao exposto, o objetivo deste artigo foi " analisar as concepções pedagógicas orientadoras da formação em enfermagem e a associação para a efetivação do cuidado clínico". Neste texto procuramos refletir sobre a prática docente do ensino do cuidado clínico da enfermagem, uma tarefa complexa por abranger diversas perspectivas que vão desde as concepções pedagógicas e metodológicas de ensino e avaliação, perpassando pelas concepções de saúde, clínica, enfermagem e cuidado com vistas a efetivação da política pública de saúde vigorante.

\section{Material e Métodos}

Pesquisa exploratória e qualitativa realizada em três universidades em Fortaleza/CE que ofertam graduação em enfermagem. O estudo foi aprovado pelo Comitê de Ética e Pesquisa da Universidade Estadual do Ceará (CEP/UECE), segundo o parecer $\mathrm{n}^{\mathrm{o}} 574.280$ de $21 / 03 / 14$, que atesta o seguimento da Resolução n ${ }^{\circ}$. 466/12 do Conselho Nacional de Saúde (CNS).

A escolha pelo cenário da pesquisa se deu por conveniência do pesquisador. Um recorte da realidade em estudo no intuito de conhecer as facetas do ensino superior de enfermagem nesta localidade que é a cidade de Fortaleza/CE, por esta se constitui uma referência educacional para o Norte e Nordeste brasileiro, tanto a nível de graduação, como pós-graduação, tanto a nível público, como privado.

Os cenários de pesquisa foram visitados com o objetivo de convidar os sujeitos aptos segundo os critérios de inclusão: atuar como professor efetivo junto à instituição selecionada; ter formação acadêmica em enfermagem; exercer sua prática docente em componentes curriculares, cujo enfoque ementário seja o cuidado clínico em enfermagem. Foram excluídos, participantes cumprindo afastamento laboral (licença médica, capacitação, prêmio, férias ou sem remuneração). Ao final, 30 docentes assinaram o Termo de Consentimento Livre e Esclarecido (TCLE) atestando a participação voluntária ao estudo.

A coleta dos dados ocorreu nos meses de julho a agosto de 2014, o agendamento prévio foi necessário 
para que o instrumento fosse aplicado individualmente pelo pesquisador, as entrevistas semiestruturadas foram gravadas no local de trabalho dos participantes. A primeira parte do instrumento é composta por questões fechadas e coletou dados pessoais e profissionais tabulados usando estatística descritiva e caracterizam os participantes. A segunda é composta por questões abertas e concerne a entrevista sobre formação, trajetória profissional e prática docente para o ensino do cuidado clinico de enfermagem. $O$ fechamento amostral ocorreu no momento que as respostas se tornaram repetitivas e sobreveio novas adesões voluntárias ao estudo.

Após a transcrição das entrevistas, principiou a fase das análise interpretativa dos dados seguindo as etapas metodológicas da Análise de Conteúdo: (1) préanálise, que consistiu na leitura atenta das respostas às questões abertas cujo objetivo era encontrar o núcleo de sentido no texto confrontando-os com objeto de estudo; (2) exploração e tratamento dos resultados, após encontrados os núcleos de sentidos as categorias de análise emergiram e estas compõem os resultados qualitativos; (3) inferência, ao serem encontrados os resultados, as conclusões foram colocadas para a (4) interpretação e discussão, para isso tomou-se por base outras informações, percepções, argumentos de outros autores sobre o objeto de estudo (BARDIN, 2011)

Com o intuito de preservar o sigilo $\mathrm{e}$ confidencialidade dos dados, atitudes foram adotadas no sentido de codificar as entrevistas. Para tal fim, optamos pela não-identificação da instituição que o docente atua. Como também, ao publicar as falas que compõe os resultados deste estudo, os entrevistados serão identificados com a letra "D" de "Docente", seguido de números arábicos na ordem crescente, conforme se processou a coleta de dados.

\section{Resultados}

Participaram do estudo 30 docentes-enfermeiros das Instituições de Ensino Superior (IES) selecionadas, 10 são ligados a IES 1, 10 a IES 2 e 10 a IES 3. A maioria é do sexo feminino $(\mathrm{n}=28)$, idade superior a 40 anos $(n=26)$. Sendo que 26 concluíram a graduação em enfermagem há mais de 12 anos; 14 atuam na docência há mais de 20 anos e 12 há mais de 10 anos. Quanto a titulação, 24 são doutores e 6 são mestres.

As entrevistas passaram por análise de conteúdo e emergiram três categorias: (A) Formação e Trajetória profissional; (B) Concepções sobre Cuidado, Clínica e Enfermagem; e (C) Concepções Pedagógicas para o Ensino do Cuidado Clínico em Enfermagem.

$\mathrm{Na}$ categoria A "Formação e Trajetória profissional" pondera-se sobre as formas e razões que conduziram o entrevistado ao encontro com a docência, apresentando aspectos marcantes vividos no início do magistério superior e os desafios/ dificuldades no cotidiano da sala de aula.

Notabiliza-se que eventos de ordem pessoal explicam a inserção e permanência no ensino superior de enfermagem, que podem ser constatados pelos relatos sobre as vivências, conquistas e esforços individuais no transcorrer da graduação e pós-graduação. Essas falas representam elementos determinantes para atuar na docência:

[... o desejo surge, por meio do programa de Educação Tutorial (PET), ainda durante a graduação. (D1)

Sempre achei que tinha habilidades para ensinar. $E$ antes de me formar já havia tido experiência com ensino, pois fui bolsista de monitoria. Depois fui convidada para ministrar cursos de capacitação e concorri a seleção na Universidade. (D4)

Minha inserção foi através no ensino de graduação, pesquisa e extensão, [...] especialização, mestrado e doutorado. (D10) (D23)

Ao final do mestrado fui convidada a lecionar.

Os relatos atestam que a docência surge de uma eventualidade, desejo ou inclinação pessoal. Mas, aponta os espaços acadêmicos onde esse desejo nasceu, ou seja, ainda na graduação, mediante a inserção em atividades institucionalizadas de pesquisa e extensão, programas de monitoria e o Programa de Educação Tutorial (PET), microespaços de formação que potencializam o professorado em enfermagem e se consolidou após a conclusão da pós-graduação stricto sensu.

As falas a seguir descrevem como os entrevistados ingressaram no ensino superior de enfermagem, os docentes revelam a atividade de professor como algo secundário ao agir do enfermeiro. Embora demonstrem identificação com a profissão, os relatos mostram que a docência surge na vida dos participantes como 'nova descoberta', não fora, portanto, uma escolha consciente. Os determinantes do ingresso na docência são multifatoriais:

Desde o terceiro semestre da graduação decidi que um dia seria professora. O envolvimento com a pesquisa consolidou este desejo (D12)

Escolbi a trajetória de ensino superior porque é gratificante há mais pontos positivos do que negativos. (D17)

Sobre os desafios e dificuldades para atuar na docência, os participantes colocam questões ligadas

HU Revista, Juiz de Fora, v. 43, n. 4, p. 339-347, out./dez. 2017 
a cultura organizacional e infraestrutura das IES, relações de trabalho, necessidade de maior número de colaboradores em determinados componentes curriculares, excesso de atividades exigidas em relação ao ensino, pesquisa e extensão e a perda da autonomia:

Os desafios, porém, dizem respeito a faculdade particular que tem um modelo baseado no lucro, ao invés da formação com competência e o professor é um objeto nesse contexto sofrendo várias condições como perda da autonomia, ainda há pouco investimento e uma grande deficiência na pesquisa e extensão. (D4)

Acredito que o maior desafio é o acumulo de tarefas a serem desenvolvidas na área de ensino, pesquisa e extensão, sobretudo porque há poucos professores na minha disciplina na IES. (D6)

Trabalho com responsabilidade, mas as dificuldades da IES quanto a burocracia e infraestrutura nos desestimula às vezes. (D8)

Escolbi a trajetória de ensino superior porquê e gratificante há mais pontos positivos do que negativos. (D17)

A cultural organizacional, burocrática e não democrática nas instituições pode determinar a insatisfação profissional, associado ao não investimento na capacitação docente, infraestrutura precária e relações de trabalho desgastantes. Situação que gera, por consequência, falhas na prática docente e déficits de aprendizagem por parte dos alunos. Os depoimentos expõem os achados:

A única coisa que me deixa preocupada é o nivel dos alunos que estão em sala de aula e serão futuros enfermeiros. (D10)

Tornei-me mais rígida e preocupada com a qualidade da aprendizagem, no entanto, mais ainda comprometida com a equidade. (D12)

Eu sonhava em mudar o mundo, hoje se conseguir mudar algo na sala de aula, já fico feliz. Fiquei mais pé no chão. (D15)

[...] até o momento não realizei outros cursos de formação pedagógica apenas disciplinas no mestrado e doutorado. (D18)

Na categoria B "concepções sobre cuidado, clínica e enfermagem" buscou-se identificar as concepções dos docentes sobre cuidado, clínica e enfermagem e como esses conceitos se inter-relacionam para orientar a prática docente para o ensino do cuidado clínico em enfermagem.

Sobre a definição de cuidado, os participantes colocam como uma difícil tarefa que requer ressignificações e clarificação mediante novos estudos. Atributos carregados de objetividade, mas, também, de subjetividade, são colocados como definidores desse conceito, como observado nos relatos que se seguem:

É muito dificil conceituar cuidado. Em meus anos de profissão ainda não encontrei sua real definição. (D11)

O ser bumano é cuidador em potencial. E o cuidado na enfermagem mais especificamente, ele não pode estar desarticulado desses outros cuidados instintivos. (D18)

É como o amor, dificil de conceituar. Mas, talvez o cuidado seja a preservação correta, amorosa e eficaz. da vida elou do bem-estar dos seres vivos que na Enfermagem aprendemos a fazer de maneira cientifica, técnica e organizada. (D20)

Sob o olhar dos participantes, o cuidado, ainda,

[... é aprendido na Enfermagem, como noção básica e filosófica do cuidado, pois ele também tem que estar no plano das ideias da enfermeira. (D13)

Talvez o cuidado seja a preservação correta, amorosa e eficaz da vida e/ ou do bem-estar dos seres vivos que na Enfermagem aprendemos a fazer de maneira cientifica, técnica e organizada. (D18)

O cuidado é visto como fruto do debate de ideias e da interdisciplinaridade de saberes e práticas. Concebido na perspectiva da integralidade, o cuidado assume uma expressão polissêmica, por olhar o homem para além da dimensão biológica de seu processo de saúde e adoecimento. Para os docentes, o cuidado também significa:

Atenção dispensada a alguém que necessita de intervençôes para melhorar a sua saúde e a qualidade de vida. (D24)

Deve ser individualizada e sempre bumanizadora. (D9)

Ao serem questionados sobre o conceito de clínica, os docentes assim a definiram:

É a ação de desenvolver, sistematicamente, a avaliação de saúde, diagnóstico e prescrição da situação de saúde de uma pessoa. (D3)

Especialidade no atendimento da saúde, principalmente especialidade médicas. (D4)

É o estudo e investigação de sinais e sintomas das alterações e distúrbios. (D17)

Pelos relatos, apercebe-se que a ideia de clínica é construída numa perspectiva da biomedicina, na qual o cuidado volta-se para o adoecimento do corpo; cuidar demanda procedimentos técnico-científicos, tratamentos medicamentosos, e, consequentemente, 
a cura. Assim, desconsidera outras perspectivas de conceituação. A clínica aparece atrelada à procedimentos técnicos e de administração de pessoas e processos que visam o cumprimento da sistematização da assistência de enfermagem.

Outros relatos apresentam a necessidade de ressignificar a clínica, sugere rupturas com o conceito original numa tentativa de gerar novos sentidos e possibilidades práticas que priorizem a integralidade do cuidado. Uma clínica cujo foco é o sujeito e suas significações e vivências do adoecimento, o cuidado de saúde realizado por equipe multiprofissional, a promoção à saúde e a prevenção de doenças e agravos.

É a avaliação e assistência em saúde de um individuo. Na versão ampliada do sujeito atua de forma mais participativa e pensa-se essa avaliação no plano coletivo. (D5)

É a ação de desenvolver a atenção preventiva ou não à saúde de outrem. (D11)

Espaço de atenção integral, que vê o ser humano de maneira integralizada não só ao ser doente ou em déficit de cuidado, mas sim aquele que é ator em sua vida e que merece atenção e orientação para a manutenção da saúde. (D12)

Finalmente, procuramos conhecer de que forma as concepções de cuidado e clínica expressas norteiam a prática pedagógica dos docentes ao executarem suas aulas, avaliações, articulações com outros espaços da formação, seja os serviços de saúde, de educação, entre outros, ao formarem enfermeiros.

Minhas avaliações visam estimular o aluno a mostrar a sua sustentabilidade, seus conhecimentos mais universalizados e seus estágios nos serviços eles são estimulados a pratica em um cuidado humanizado e voltado para as necessidades sociais, políticos $e$ emocionais/mental dos clientes. (D3)

Norteiam completamente, tanto nas aulas teóricas quanto práticas e na convivência com colegas docentes e discentes. (D10) (D13)

Norteiam integralmente de forma transdisciplinar.

$\mathrm{Na}$ relação com outros alunos, com profissionais do serviço, nas aulas em minha postura profissional. (D22)

O meu foco é a relação teoria e prática e suas concepções estão diretamente relacionados a isso. (D26)

$\mathrm{Na}$ categoria C "Concepções Pedagógicas para o Ensino do Cuidado Clínico em Enfermagem" buscamos identificar as formas como os docentes desenvolvem a prática pedagógica e que aprendizagem foram adquiridas na trajetória profissional. Os relatos em sua maioria descrevem uma prática pedagógica tradicional no cotidiano do ensino superior de enfermagem.

Sou tradicionalista. Aulas expositivas, demonstrações da prática, leitura de artigos, discussão em grupo. Valorizo muito as experiências pessoais. (D2)

Não gosto de técnicas didáticas muito agitadas. Pois levam a superficialidade, muita técnica de dinâmica integrativas denominadas participativas deixam a desejar no conteúdo. (D22)

Ao mesmo tempo que se colocam como tradicionalistas, os docentes se descrevem como sujeitos que primam pelo seguimento de métodos inovadores ou metodologias ativas.

Tento sempre relacionar teoria e prática, fundamentando com exemplos da prática da enfermagem. (D4)

Para aliar a teoria à prática, uso de laboratório, estudo de caso, práticas (estágios) nos campos de atuação. (D14)

A teoria e prática estão aliadas no exercício da enfermagem. (D18)

Desenvolver um olhar critico reflexivo é automaticamente desenvolver uma prática aliada a teoria. (D20)

Baseada em metodologias ativas, principalmente com a arte-educação, questões reflexivas e leitura acadêmica. (D23)

Há preocupação, para que o docente seja capaz de assumir a responsabilidade em contextualizar a teoria e a prática, demostrar a aplicabilidade dos conteúdos curriculares com o trabalho em saúde e enfermagem e integrar o aluno a realidade mediante metodologias ativas, como demonstra os relatos:

Fazer conexões com outras disciplinas, principalmente das áreas humanas/sociais para que o aluno tenha senso crítico e veja o mundo e a enfermagem de forma holistica e atualizada. (D3)

Interação e integração do grupo discente e docente. Relação constante com a realidade prática e a teoria. Resgata experiências e vivencias profissionais relacionadas aos conteúdos teóricos ministrados sobre a prática. (D12)

[...] Uso de laboratório, estudo de caso, práticas (estágios) nos campos de atuação. (D14)

No que se refere a inovação da prática pedagógica, os entrevistados apontam ser importante renovar suas metodologias de ensino. Mas, ainda predomina certa acomodação seja por medo ou desmotivação para buscar novos horizontes: 
Procuro atualizar e reinventar sempre. (D1)

Meios de comunicação virtual, com internet. Recursos visuais de Datashow, arte rodas de conversas, seminários com arguição, incentivo à prática, atividades complementares a prática. (D3)

Extremamente necessário a inovação e utilização de outras práticas, uso de tecnologias. (D16)

Tento me manter atualizada e trabalhar na sala de aula as inovacões da profissão. (D25)

Entretanto, também identificamos a visão crítica e inovadora do ensino como orientadora da prática docente no sentido da efetividade do cuidado clínico autônomo, autêntico, potencializador e transformador. A fala do participante "[...]atuo com autonomia e tentando imprimir esta autonomia nos discentes. (D27) " dá um indicativo do desejo presente no professor de objetivar e inovar as suas práticas e concepções de ensino.

\section{Discussão}

Os resultados retratam um perfil acadêmico e profissional de professores experientes e qualificados para atuar no ensino superior de enfermagem, tal constatação pode ser feita ao analisarmos o tempo no exercício na docência e a formação desses profissionais a nível de doutorado e mestrado.

Entretanto, ser docente requer responsabilidade ética, política e profissional, além da permanente disposição para o aprender. $O$ professor ao ensinar se apropria de certo conteudo específico, o que não quer dizer, que ele esteja preparado, visto que o ato de ensinar exige competências e habilidades técnicas e pedagógicas as quais devem ser aprendidas na escola e aprimoradas ao longo da vida (CHAVES; CECCIM, 2015).

É imprescindível ao aspirante ao professorado ter capacidade de criar, formar opinião e interagir no ambiente social nas diversas áreas de produção do conhecimento. Assim, para ensinar o cuidado clínico em enfermagem o docente deve orientar sua ação pedagógica no apoio à vida e no desenvolvimento social e cidadão. Além de deter/construir conhecimento técnico-científico sobre os conteúdos curriculares sob a sua responsabilidade. $\mathrm{O}$ ingresso na carreira docente é um momento repleto de insegurança e ansiedade. $O$ trajeto para se tornar professor é bastante significativo para os jovens docentes e tais significações carregam em si a essência da docência (CRUZ et al., 2017).

Em sua "formação e trajetória profissional" o docente constrói diversos saberes e práticas relacionados à sua profissão provenientes da sua formação acadêmica, dos currículos acumulados, das instituições de formação, do próprio cotidiano e do exercício consciente de sua prática pedagógica. Tais saberes o permitem repensar e redimensionar sua prática. Nesse contexto, a formação pedagógica permanente torna-se imprescindível para a valorização da docência. Este deve ser um processo dinâmico que articule os saberes da experiência, saberes disciplinares, saberes curriculares e saberes pedagógicos, tecendo um verdadeiro processo de construção e reconstrução de suas práxis mediante a crítica e a reflexão (RODRIGUES; MENDES SOBRINHO, 2007).

Assim, é necessário qualificar o enfermeiro para o trabalho na docência mediante uma linguagem comum de formação em relação a graduação e pós-graduação, vislumbrando o processo de ensino-aprendizagem como algo interativo, capaz de libertar o docente de práticas pedagógicas autoritárias e conservadoras de modo a construir uma educação democrática e dialógica que seja capaz de fazer o aluno pensar, sentir e ser criativo em relação ao seu aprendizado (CRUZ et al., 2017; FREIRE, 2011a; FREIRE, 2011b).

As "concepções sobre cuidado, clínica e enfermagem" expressas pelos participantes demonstra uma dificuldade e/ou limitação dos docentes em conceituar os termos. Provavelmente, esta visão limitada do cuidado entendido como algo inerente ao ser humano, remete aos modos como a enfermagem historicamente associa o cuidado a prática caridosa, movida pelo zelo e amor ao próximo, uma prática altruísta por natureza. Por outro lado, alguns relatos, avançam ao apresentar a concepção de cuidado inovador que compreende a enfermagem como prática social.

$\mathrm{Na}$ enfermagem, o cuidado é genuíno e peculiar, a essência da profissão. Trata-se de um empenho transpessoal de 'ser humano' para 'ser humano'. Tem como objetivo propiciar a sensação de conforto, confiança, segurança, tranquilidade e alívio. Assim, o conforto, como resultante do cuidado clínico de enfermagem, deve ser uma das metas estabelecidas pelo plano de cuidados dos enfermeiros (WALDOW, 2009).

O cuidado clínico compreende um conjunto de práticas, intervenções e ações sistematizadas desenvolvido pela enfermagem e dirigido ao ser humano, no âmbito individual ou coletivo, fundamentado em evidências quantitativas e/ou qualitativas, com bases filosóficas, ética, estética, teóricas, científicas, técnicas e política, considerando as manifestações ou respostas das pessoas ao seu processo saúde-doença (SILVEIRA et al., 2013).

Para os docentes a clínica ressignificada influenciará o ensino do cuidado de enfermagem. 
Assumir novas concepções pedagógicas possibilitará que a aprendizagem contemple sua tripla dimensão, os saberes cognitivos (saber), práticos (fazer) e atitudinais (ser e estar) (SILVEIRA et al., 2013).

Assim, a clínica ampliada é apresentada como outra possibilidade conceitual para a docência em enfermagem. Nesta perspectiva busca-se a superação da fragmentação assistencial e do tecnicismo do processo de trabalho em saúde/enfermagem centrado em atos e procedimentos prescritivos, construídos numa relação vertical entre o profissional que presta o cuidado e o sujeito que recebe o cuidado. Repensar a clínica deve assentar-se no deslocamento do cuidado com ênfase na doença para centrá-lo sobre o sujeito concreto. Concebe uma rede assistencial assentada num território vivo, onde os serviços se articulam em uma teia que envolve aqueles que recorrem aos serviços em busca de cuidado, orientando-se na coresponsabilização pelas necessidades do sujeito por parte de todos os níveis assistenciais (CAMPOS; AMARAL, 2007).

Acredita-se, que enfermeiro-docente à medida que ensina também aprende. Este processo o torna sujeito ativo e responsável pela produção de conhecimento. Assim, a docência transforma-se em fonte de conhecimento e construção de saberes. Ensinar exige, dentre outras coisas, a consciência de que o conhecimento é algo inacabado exigindo a reflexão crítica da prática e a tomada consciente de decisões (CRUZ et al., 2017; RODRIGUES; MENDES SOBRINHO, 2007).

Pensar nas "concepções pedagógicas para o ensino do cuidado clínico de enfermagem" necessárias para ensinar é fazer com que os atores que atuam na formação (docentes, discentes, gestores dos serviços e comunidade) reflitam sobre a necessidade de mudanças que respondam as tendências e necessidades da sociedade.

O desenvolvimento da prática pedagógica a partir de uma ação docente reflexiva e baseada no diálogo, na troca de experiências, na investigação e na aplicabilidade dos conteúdos requer maior envolvimento de todos os sujeitos do processo de ensino-aprendizagem. As competências exigidas para atuar na docência perpassam pela capacidade de articular os componentes curriculares com a realidade social e de saúde na qual o aluno está inserido (SILVA; SOUZA; FREITAS, 2011).

O diálogo entre teoria e prática possibilitará o desenvolvimento de uma ação transformadora da realidade. Considerar a vivência dos alunos no contexto real do trabalho em saúde em que a prática se torna o verdadeiro fundamento da teoria é o meio legítimo de produzir ciência (SILVA; SOUZA; FREITAS, 2011).

Percebe-se, que ainda persiste uma pedagogia tradicional na prática docente e isto não oportuniza a interação professor-aluno de forma democrática e dialógica. Os que defendem os métodos de ensino tradicionais como elementos imprescindíveis argumentam que determinados conteúdos, principalmente, os técnicos, somente poderão ser ensinados e aprendidos pelo seguimento desses modos de ensinar.

Para assumir concepções e práticas pedagógicas inovadoras e ativas se faz necessário que o docente se convença de que não é mero ensinante ou mero especialista da docência, mas, sim militante político da educação, um professor nato. Essa ação não se limita apenas ao ensino dos componentes curriculares, exige o compromisso e engajamento na luta pela superação das injustiças sociais. A inovação pedagógica implica mudanças nas concepções e práticas pedagógicas e, essas mudanças, envolvem sempre um posicionamento crítico, explícito ou implícito, face às práticas pedagógicas tradicionais (CRUZ et al., 2017; BELLO; BUENO, 2012).

A era da informação e da tecnologia força a necessidade para inovar e fortalecer os elos que instituem o processo de ensino-aprendizagem, faz com que o conhecimento seja melhor absorvido e vivenciado. Mas, para aprender a inovar é necessário que haja educação permanente dos docentes para eles aprenderem a ensinar a inovar. O uso de práticas inovadoras de ensino é importante pois promovem motivação, organização, gestão da informação, conhecimento, inovação, tecnologia, assim como melhora as relações humanas entre professor e aluno (CRUZ et al., 2017; GUSMÃO; CECCIM;

DRACHLER, 2015).

\section{Conclusão}

A formação em enfermagem demanda por transformações pedagógicas expressivas, pois, a continuidade da pedagogia tradicional precisa ser superada por metodologias ativas e inovadoras. $\mathrm{O}$ uso das novas tecnologias, e a consequente rapidez como a informação flui, associado as mudanças nos estilos de vida das pessoas, requer flexibilidade e criatividade dos profissionais que lidam o cuidado às populações, bem como, dos docentes que ensinam as pessoas para exercer as profissões da saúde.

Cabe ao professor utilizar/construir os recursos e conhecimentos para proporcionar aos seus alunos a capacidade de crítica e reflexão da realidade e autonomia para sua transformação. Os alunos devem ser ensinados a construir o seu próprio

HU Revista, Juiz de Fora, v. 43, n. 4, p. 339-347, out./dez. 2017 
conhecimento. O professor assume a função de mediador do aprendizado, ele precisa sentir-se capaz para atuar na docência e superar os seus desafios. Para isso é necessária uma política de capacitação capaz de responder as necessidades da formação, além do desprendimento de esforços individuais, coletivos e institucionais, num processo de interação, integração, comprometimento e diálogo.

As limitações do estudo refletem sua característica de ser um estudo regional e por atingir um pequeno universo amostral, entretanto, para sua natureza qualitativa não há maiores prejuízos. Os questionamentos realizados nas entrevistas apenas apontam a ponta do iceberg da problemática que emerge nas categorias analisadas. Se faz necessário, portanto, aprofundamentos sobre os temas em discussão presentes nas falas dos participantes, em especial, sobre as implicações da cultura organizacional (gestão da formação em saúde) presentes nas instituições de ensino superior, as quais se apresentam na fala dos participantes como determinantes para a insatisfação da carreira docente na contemporaneidade e, também, estudos que busquem analisar os conceitos de cuidado, cuidado clinico e cuidados clínicos de enfermagem, tão importantes para fundamentação de projetos pedagógicos de formação de enfermeiros.

\title{
Conceptions and pedagogical practices of teachers for the clinical care of nursing
}

\begin{abstract}
Exploratory and qualitative research whose objective was to analyze the conceptions and pedagogical practices in the nursing training for effective clinical care. 30 teachers-nurses from two public universities and one from Fortaleza / CE participated in the study. Data collection took place through a semistructured interview. After content analysis, three categories emerged: (A) Professional Formation and Trajectory; expresses the motivations of the nurses to act in the teaching, for the interviewees the act of teaching arises during their professional trajectory as a natural and personal event; (B) Conceptions on Care, Clinic and Nursing, reveals how the teachers define nursing clinical care, this seen as an act of solidarity based on scientific and practical knowledge of nursing and other sciences. Care should be based on integrality with a view to the effectiveness of the expanded clinical practice and (C) Pedagogical Conceptions for Nursing Clinical Care Teaching, exposes the thinking and doing of nursing when acting in the training of nurses, in this category the interviewees state that despite the strong attachment to the use of traditional pedagogy, in the everyday classroom is perceptible methodological changes in teaching practice that seek to build a critical and reflective nursing. Thus, in order to create a dynamic and innovative nursing, it is necessary that the teaching practice overcome challenges inherent to the teaching of clinical nursing care in order to re-signify the pedagogical conceptions and practices that guide the formation, the construction of science and the qualification for teaching in the area.
\end{abstract}

Keywords: Nursing faculty practice. Teaching. Nursing care.

\section{REFERÊNCIAS}

Bardin, L. Análise de conteúdo. São Paulo: Edições 70, 2011.

Bello, I. M.; Bueno, B. O. Programas especiales de formación superior de profesores en Brasil: la universitarización del magisterio en cuestión. Archivos Analíticos de Políticas Educativas, v. 20, n. 6, p. 1-22, fev. 2012.

Campos, G. W. S.; AMARAL, M. P. A clínica ampliada e compartilhada, a gestão democrática e redes de atenção como referenciais teóricos operacionais para a reforma do hospital. Ciência Saúde Coletiva, v. 12, n. 4, p. 849-859, ago. 2007.

Ceccim, R. B.; Merhy, E. E. Um agir micropolítico e pedagógico intenso: a humanização entre laços e perspectivas. Interface (Botucatu), v. 13, Supl. 1, p. 531-542, 2009.
Chaves, S. E.; Ceccim, R. B. Avaliação externa no ensino superior na área da saúde: inquietações e a dimensão das margens. Interface (Botucatu), v. 19, n. 55, p. 1233-1242, dez. 2015.

Cruz, R. A. O. et al. Reflexões à luz da teoria da complexidade e a formação do enfermeiro. Revista Brasileira Enfermagem. v. 70, n. 1, p. 236-239, fev. 2017.

FREITAS, D. A. et al. Saberes docentes sobre processo ensinoaprendizagem e sua importância para a formação profissional em saúde. Interface (Botucatu), v. 20, n. 57, p. 437-448, jun. 2016.

Freire, P. Educação como prática da liberdade. 34. ed. Rio de Janeiro: Paz e Terra, 2011a. 
Freire, P. Pedagogia da autonomia: saberes necessários à prática educativa. 43. ed. Rio de Janeiro: Paz e Terra, 2011b.

Gadotti M. Perspectivas atuais da educação. Porto Alegre: Artes Médicas, 2000.

Gusmão, R. C.; Ceccim, R. B.; Drachler, M. L. Tematizar o impacto na educação pelo trabalho em saúde: abrir gavetas, enunciar perguntas, escrever. Interface (Botucatu), v. 19, supl. 1, p. 695-707. 2015.

Souza, c. j.; Valente, G. S. C. Formação pedagógica do enfermeiro docente baseada em competências: exigência ou necessidade? European Journal of Education Studies, v. 3, n. 3, p. 242-251, fev. 2017.

Rodrigues, M. T. P.; Mendes Sobrinho, J. A C. Enfermeiro professor: um diálogo com a formação pedagógica. Revista Brasileira Enfermagem, v. 60, n. 4, p. 456-459, jul./ago. 2007.
Santos, E. C. G dos S et al. Por uma epistemologia de enfermagem: versões e interpretações para cuidado em saúde. Revista Saúde e Desenvolvimento. v. 11, n. 6, p. 1-8, jan./mar. 2017.

Silva, M. J.; Sousa, E. M.; Freitas, C. L. Formação em enfermagem: interface entre as diretrizes curriculares e os conteúdos de atenção básica Revista Brasileira Enfermagem, v. 64, n. 2, p. 315-321, abr. 2011.

Silveira, L. C. et al. Clinical care in nursing: development of a concept in the perspective of professional practice reconstruction.

Escola Anna Nery. v. 17, n. 3, p. 548-554, ago. 2013.

TEIXEIRA, E. Em tempos de novas Diretrizes Curriculares Nacionais (DCN) para o curso de graduação em Enfermagem. Revista Enfermagem UFSM. v. 7, n. 2, p. 3-4, abr./jun. 2017.

Waldow, V. R. Momento de cuidar: momento de reflexão na ação. Revista Brasileira Enfermagem, v. 62, n. 1, p. 140-145, fev. 2009. 